\title{
Literatura de la levedad. La prosa inicial de Felisberto Hernández
}

\section{Literature of Lightness. The Initiall Prose of Felisberto Hernández}

\author{
Cecilia Rubio Rubio \\ Universidad de Concepción, Región del Biobío, Chile \\ Contacto: crubio@udec.cl \\ http://orcid.org/0000-0003-1645-961X
}

\section{RESUMEN}

En este artículo, cuyo objeto de estudio es la prosa inicial del escritor uruguayo Felisberto Hernández, que va de 1925 a 1931, y su vinculación con el concepto de levedad propuesto por Ítalo Calvino en su Seis propuestas para el próximo milenio, comenzaré por revisar el estado de la cuestión, empezando por los comentarios admirativos que el propio Calvino prodigó a la obra de Felisberto Hernández, para luego comentar la crítica felisbertiana. En un segundo y tercer lugar, me centraré en la levedad en tanto valor literario y en el análisis de su presencia en la obra felisberteana. Arriesgo aquí una definición y una caracterización del valor de la levedad, que Calvino presentó de manera fluida. Al articular y sistematizar la ocurrencia de la levedad en esta obra temprana, mi objetivo es demostrar que ella hace de la levedad uno de sus rasgos característicos, con lo cual -sin dejar de ser singularse puede insertar en una tradición literaria que está formada tanto por narradores y obras asociadas a la vanguardia latinoamericana, como por escritores de tradición europea de siglos pasados. Con esto pretendo contribuir a ir señalando una serie, una trayectoria $y$, en definitiva, una tradición literaria común que ocupa un espacio teórico aún poco estudiado y en la cual una obra como la de Felisberto Hernández encuentra un lugar donde hermanarse.

Palabras clave: Levedad; Ítalo Calvino; Felisberto Hernández; Primeras invenciones; Vanguardia

\section{ABSTRACT}

In this article, whose object of study is the initial prose of the Uruguayan writer Felisberto Hernández, which goes from 1925 to 1931, and its connection with the concept of lightness proposed by Ítalo Calvino in his Six Proposals for the Next Millennium, I will begin by reviewing the state of the question, beginning with the admiring comments that Calvino himself lavished on the work of Felisberto Hernández, to later comment on the Felisbertian criticism. In a second and third moments, I will focus on lightness as literary value and on the analysis of its presence in the work of Felisberto. I risk here a definition and a characterization of the value of lightness, which Calvin presented in a fluid way. By articulating and systematizing the occurrence of lightness in this early work, my objective is to show that she makes lightness one of its characteristic features, with which - without ceasing to be singular - it can be inserted into a literary tradition that is formed both by narrators and works associated with the Latin American avant-garde, as well as by writers of the European tradition of past centuries. With this I intend to contribute to pointing out a series, a trajectory and, ultimately, a common literary tradition that occupies a theoretical space that is still little studied and in which a work such as that of Felisberto Hernández finds a place to be united.

Keywords: Lightness; Ítalo Calvino; Felisberto Hernández; First Inventions; Avant-garde 


\section{1. Ítalo Calvino y Felisberto Hernández. Estado de la cuestión}

A juzgar por los escritos que Ítalo Calvino dedicó a Felisberto Hernández (Montevideo, 1902-1964), su entusiasmo por la obra felisberteana es representativo de los valores literarios que más le interesaban y que ponía en práctica. Sin embargo, en el escrito más citado y recurrido por los críticos, no encontramos menciones explícitas a la levedad. Allí, Calvino (2009) destaca las cualidades que harían de Felisberto Hernández un escritor singularísimo, sin parangón entre los latinoamericanos y los europeos. Entre ellas, interesan en este momento las que guardan alguna relación con los rasgos de la levedad, por ejemplo, la asociación de ideas como juego predilecto de los personajes y del autor, y también como procedimiento de construcción de los relatos, a la manera de una composición musical. Otra cualidad es la tensión entre la imaginación bien concreta y "la palabra que le sigue a tientas" (Calvino, 2009, p. viii); de esa tensión surge una sugestión que puede compararse a la que emana de un cuadro naif. Para Calvino, lo que más sorprende de la obra felisberteana es la forma de presentar el carácter físico de los objetos y de las personas. Esta fisicidad del mundo se expresa también en el hecho de que las sensaciones que producen objetos y personas provocan en los protagonistas - dice Calvino - algo como "ecos visuales" que mantienen su repercusión en la mente del lector.

Respecto de la vinculación entre la obra felisberteana y la propuesta de Calvino (2001) sobre la levedad, un par de textos ha esbozado su pertinencia crítica. Ambos textos, sin embargo, consideran la levedad como un rasgo entre varios otros, y en un sentido muy parcial. Alicia Martínez, en su nota de 2007, la ha ligado a la cuestión de la mirada oblicua en Felisberto Hernández, mirada "al sesgo", dice, "un poco a la manera en que (de nuevo recurrimos a Ítalo Calvino) aparece la visión de la literatura en 'Levedad"' (p. 133). A mi parecer, esta constatación de cercanía entre Felisberto Hernández y la levedad aparece como una intuición que no tiene mayores consecuencias, lo mismo que la cercanía con la vanguardia, dado que Martínez se sigue sirviendo de Calvino para citar la mil veces citada frase - que a estas alturas funciona como una boutade, y que es lo que intento discutir en este artículo- de que "Felisberto no se parece a nadie" (p. 136).

La segunda aproximación a la relación entre la obra de Felisberto Hernández y la propuesta de Calvino es la que realiza Fabio Rodríguez Amaya (2017) en "Nadie encendía las lámparas de Felisberto Hernández y los cinco postulados de Las lecciones americanas de Ítalo Calvino". Se trata de una propuesta más general que la realizada aquí, porque involucra los cinco principios o valores literarios planteados por Calvino (2001), de los cuales la levedad es uno; y más acotada, porque está centrada en un solo relato felisberteano. Pero, también es más general, porque Rodríguez Amaya no escudriña en el concepto de levedad, sino que su escritura va saltando de un concepto a otro o, mejor dicho, de un valor a otro, de los que Calvino aporta: levedad, rapidez, exactitud, visibilidad y multiplicidad. En referencia a la levedad, Rodríguez Amaya parte, al igual que Calvino, de la mirada indirecta de Perseo, para realizar el parangón con un Felisberto Hernández que se aparta del regionalismo y del telurismo, pues "Solo así, con la mirada oblicua, y la imagen refractada, se captaría lo nimio, lo banal, lo simple, lo sencillo que es en realidad, como lo real compone al mundo, sin recurrir a los máximos sistemas" (2017, p. 151).

La lectura de Rodríguez Amaya se aproxima a la mía en el sentido de que ve en Felisberto Hernández (pero también en Calvino, Duchamp, Macedonio y Torres García - a ello agregaría a Juan Emar-) el conocimiento y la plasmación de una urgencia: "la necesidad de conjunción entre lo estático y lo dinámico, lo invariable y lo fluctuante, lo nimio y lo trascendente" (2017, p. 153). Además, Rodríguez Amaya comprende que la levedad no es en Felisberto Hernández un recurso, sino un rasgo formal, estructural y lingüístico; a lo "agobiante del mundo", Felisberto y Calvino le opondrían "la ligereza del ser" (2017, p. 154). A esto agrega una idea que está en mayor consonancia con lo que planteo aquí y que hago extensiva a la narrativa de vanguardia: "Al desvirtuar la solemnidad (no los temores, ni el pálpito) del literato, Felisberto hace concurrir en una única entidad la melancolía y el humorismo, la ciencia y la poesía, lo cómico y lo triste" (Rodríguez Amaya, 2017, p. 154). 
Con esta manera de aligerar la distancia entre los contrarios, cuestión que la vanguardia tuvo como uno de sus objetivos, Felisberto no solo inserta en ella su obra temprana, sino que comienza a encontrar a sus pares, iluminando parentescos y afinidades que, sin romper su singularidad, permiten pensar en un tipo de literatura al que llamamos de la levedad.

\section{La levedad}

Para comenzar, adelanto la definición de la levedad que es posible elaborar a partir de los planteamientos de Calvino que revisaré a continuación. La levedad es una propiedad (un valor, una cualidad) de los textos literarios que consiste en una actitud de quitar peso al mundo (diegético) a través de un punto de vista narrativo que se caracteriza por una mirada indirecta y disolvente de la compacidad.

$\mathrm{Al}$ proponer el concepto de levedad como uno de los valores literarios rescatables para este milenio, Calvino (2001) parte de un supuesto suyo sobre la realidad y el mundo, y sobre el oficio escritural: "[...] la pesadez, la inercia, la opacidad del mundo, [son] características que se adhieren rápidamente a la escritura si no se encuentra la manera de evitarlas" (p. 20). Esta manera es justamente la levedad, ya que, dice, "sólo la levedad puede vencer a la pesadez" (p. 20). Como se observa aquí y en otros momentos de su ensayo, por un lado, Calvino trata la levedad casi siempre en concomitancia con la pesadez, como si formaran un binomio estructural tanto del mundo como de la obra literaria, y, por otro, como si la levedad fuera una virtud relativa, cuyo valor depende del peso que intenta contrastar. Quizá sea por ello que para Calvino el mito de la lucha de Perseo contra la pesada Medusa funcione como alegoría de la relación entre el escritor y el mundo, teniendo en cuenta que la actitud que hace triunfar a Perseo sobre la Medusa es la mirada indirecta, oblicua, que dirige a esta. Desde este punto de vista, la principal función de la levedad es la de transformación, la de convertir lo pesado en leve; en este marco, la literatura cumpliría una función existencial, pues la búsqueda de la levedad sería una reacción ante el peso del vivir. Es en este contexto que Calvino recuerda la novela de Milan Kundera, La insoportable levedad del ser, que sería "en realidad una amarga constatación de la Ineluctable Pesadez del Vivir" (2001, p. 23).

Existe, dice Calvino, "una levedad del pensar" (2001, p. 25), o, podemos decir también, una mirada de la levedad, que en el caso de la literatura se crea en la escritura. En tanto pensamiento o mirada que se traduce en una forma escritural, la levedad aparece asociada a la precisión y a la determinación, más que a la vaguedad y el abandono al azar; de hecho, está reñida con la frivolidad, que, comparada con la levedad, puede resultarnos pesada y opaca.

Una segunda premisa sobre la realidad permite a Calvino su propuesta de la levedad como un valor literario, y esta es que el mundo se apoya en entidades sutiles, como lo son los mensajes del ADN, los impulsos neuronales, los quarks y, en la informática, el software. A partir de estas dos premisas, a saber, la pesadez del mundo y su apoyo en entidades sutiles, se puede comenzar a abordar este a veces inestable valor de la levedad, intentando traducirlo a lenguaje conceptual, a partir de los ejemplos y comentarios a estos que hace Calvino, y con los cuales cree poder desandar un camino "muy antiguo de la historia de la poesía" (2001, p. 24). En efecto, diferenciando al poeta florentino Guido Cavalcanti, a quien nombra como "poeta de la levedad" (Calvino, 2001, p. 27), de Dante, poeta en quien "todo adquiere consistencia y estabilidad" (2001, p. 29), Calvino distingue dos "vocaciones" literarias:

Podemos decir que dos vocaciones opuestas se disputan el campo de la literatura a través de los siglos: una tiende a hacer del lenguaje un elemento sin peso que flota sobre las cosas como una nube, o mejor, como un polvillo sutil, o, mejor aún, como un campo de impulsos magnéticos; la otra tiende a comunicar al lenguaje el peso, el espesor, lo concreto de las cosas, de los cuerpos, de las sensaciones. (2001, p. 30)

En un intento de sistematización, Calvino dice haber encontrado en Cavalcanti tres acepciones de la levedad, que en rigor son tres manifestaciones: 1) "Un aligeramiento del lenguaje mediante el cual los significados son canalizados por un tejido verbal como sin peso, hasta adquirir la misma consistencia enrarecida" (2001, p. 31). Esta acepción la ejemplifica con uno de 
los breves poemas de Emily Dickinson. 2) "El relato de un razonamiento o de un proceso psicológico en el que obran elementos sutiles e imperceptibles, o una descripción cualquiera que comporte un alto grado de abstracción" (2001, p. 31). Aquí, Calvino recurre a un relato de Henry James. 3) "Una imagen figurada de levedad que cobre un valor emblemático" (2001, p. 32). En este caso, Calvino recuerda la imagen del Quijote volando en el aire y atado a la tierra solo por su lanza clavada en el aspa del molino de viento.

No obstante esta ordenación, y dado que Calvino abunda en ejemplos, es necesario continuar tratando de asir la levedad en tanto valor o cualidad literaria. Para Calvino (2001), el primer ejemplo de la vocación literaria de levedad es el libro De rerum natura de Lucrecio, del cual dice: "es la primera gran obra de poesía en la que el conocimiento del mundo se convierte en disolución de la compacidad del mundo, en percepción de lo infinitamente minúsculo, móvil y leve" (p. 24). Posteriormente, se refiere a esta misma virtud — "el atomismo de Lucrecio" (p. 35) - en el caso de las Metamorfosis de Ovidio, añadiendo la capacidad de transformación en nuevas formas de la que da cuenta este texto. En efecto, lo leve como partícula infinitesi- a la concepción del lenguaje, pues, ya en Lucrecio, Calvino advierte la idea de que las letras son átomos en movimiento continuo, que al permutarse crean las palabras. De esta manera se llega a la tradición de los pensadores para quienes el mundo guarda un secreto contenido en una combinatoria de signos escriturales, como Raimundo Lulio y los cabalistas, entre otros. Aquí la levedad aparece asociada a la metáfora del hilo de la escritura como si esta estuviera compuesta de pequeñas partículas. Pero Cyrano es, además, muy relevante por la forma en que sintió y expresó el problema de la gravitación universal, antes de Newton. Por ello, e incorporando ahora a Swift y a Voltaire, Calvino (2001) señala que, en torno a las teorías de Newton, "lo que estimula la imaginación literaria no es el condicionamiento de todas las cosas y personas a la fatalidad del propio peso, sino el equilibrio de fuerzas que permite a los cuerpos celestes flotar en el espacio" (p. 38).

A llegar al final de su recorrido por la historia de la literatura, Calvino (2001) relaciona este último aspecto de la levedad con una constante antropológica que la literatura se encarga de perpetuar, constante que enuncia como el "nexo entre levitación deseada

\section{El contraste muerte-vida, manifestado en el contraste peso-levedad es otra de las for- mas en que Felisberto Hernández se acerea a la prosa de Luciano, de Rabelais, y de vanguardistas como el chileno Juan Emar.}

mal del mundo parece sujeto a ciertas leyes de movilidad, una de las cuales sería su capacidad metamórfica. De esta manera, lo grave del mundo guarda el secreto de su levedad. Calvino incorpora luego a Cavalcanti, con lo que se agregan dos aspectos; primero, que los elementos leves de su obra se distinguen por ser vectores de información, y, segundo, que expresan la paridad de todo lo existente u "homologación de los reales", como le llama Gianfranco Contini (como se citó en Calvino, 2001, p. 28), a través de la presentación de diversas imágenes que concurren en la representación de un mismo concepto.

Todo lo señalado está relacionado con lo que Calvino llama "concepción atomista del universo", la que se combina con una fina percepción de la unidad de todas las cosas, y cuya primera manifestación en el mundo moderno la encontramos en la obra de Cyrano de Bergerac. Esta concepción atomista no escapa y privación padecida" (p. 41), que suele ser parte de un imaginario popular y que encuentra distintas manifestaciones en el vuelo a otro mundo propio de los relatos de brujas, magos y levitadores de la literatura oral. Otros aspectos que deben tenerse en cuenta se desprenden de los ejemplos de Cervantes, Shakespeare, Boccaccio y Rabelais, respecto de los cuales Calvino (2001) anota la presencia de la melancolía y el humor (humour). De la primera dice que es "la tristeza que se aligera" (p. 34), mientras que lo segundo es "lo cómico que ha perdido la pesadez corpórea" (p. 34), y que pone en duda el yo y el mundo, así como la red de relaciones que los constituyen.

La melancolía se presenta a través de los ejemplos y comentarios de Calvino (2001) como "un velo de minúsculas partículas de humores y sensaciones, un polvillo de átomos, como todo aquello que constituye la sustancia última de la multiplicidad de las cosas" (p. 
35). El ejemplo al que principalmente recurre Calvino corresponde a un texto de Shakespeare, sobre el cual afirma que posee "una especial modulación lírica y existencial que permite contemplar el propio drama como desde fuera y disolverlo en melancolía e ironía" (p. 34). Junto con ello, reconoce en Shakespeare la presencia del "fondo cultural" del Renacimiento, donde desde los neoplatónicos a los alquimistas se concibe la conexión entre macrocosmos y microcosmos, así como las mitologías clásicas y las célticas aportan con su repertorio de imágenes de fuerzas naturales de carácter sutil. Hecho este resumen, en el siguiente apartado, luego de una mirada general a la obra primera de Felisberto Hernández, enumero las notas características de la levedad, las que reviso según su presencia en dicha obra.

\section{La levedad en la prosa inicial de Felisberto Hernández}

Mirada en su conjunto, la llamada obra temprana de Felisberto Hernández - publicada entre 1925 y 1931-, y que para los críticos constituye la primera de tres etapas, conocida también como "Primeras invenciones" y como Los libros sin tapas (véase Fraga de León, 2003; Hernández, 1983 y 2010; y Díaz, 1988), ofrece como una de sus particularidades la cualidad de la levedad. Trabajaré por ello con los primeros textos de esa prosa inicial, a veces experimental en sus temas y poco adepta a la narratividad. Me refiero a Fulano de tal (1925), Libro sin tapas (1929), La cara de Ana (1930), y La envenenada (1931) (véase Hernández, 2010).

Los primeros textos corresponden más bien a microficciones, algunos sin estructura narrativa y de apariencia fragmentaria. Este es el caso de los textos de Fulano de tal y algunos de Libro sin tapas. Pareciera ser que la forma microficcional produce un efecto de levedad, ya que su contenido semántico no logra afirmarse con claridad; sin ser necesariamente abstractos, la indefinición temática juega a favor de lo inasible y lo efímero, como pasa en "Cosas para leer en el tranvía", "Teoría simplista de las almas gordas" y "De sable en mano". Los tres presentan, además, tres de los rasgos de la levedad que expondré más adelante: uno es la mezcla u oscilación entre un tema trivial y un tema serio, y otro es el humor de lo leve. El tercer rasgo recorre toda la obra de Felisberto Hernández, pues se refiere a la mirada oblicua, el punto de vista elusivo y alusivo que adopta el narrador para abordar las situaciones y hechos que narra. Esta mirada oblicua ha sido trabajada por la crítica felisberteana, al punto de que se ha convertido en una suerte de lugar común (véase, por ejemplo, Martínez, 2007, y algunos pasajes de Jorge Monteleone, 2015, especialmente, pp. 49-50).

Los libros siguientes, La cara de Ana y La envenenada, se acercan más a la estructura del relato; sin embargo, conviven bajo estos títulos prosas heterodoxas que todavía están en la línea de los dos primeros libros. De esta manera, no podemos abusar del criterio temporal en la distribución de las formas en esta primera etapa, cuya producción puede leerse, en su mayoría, como conjuntos de relatos, dando a esta última palabra el sentido algo general que suele tener en teoría de la narrativa, vale decir, el de narraciones que no siguen las técnicas del cuento clásico propuestas básicamente por Poe y Quiroga.

En síntesis, la obra inicial de Felisberto Hernández constituye una forma de literatura de la levedad, pues comparte con esta la mayoría de los rasgos que la caracterizan y que son los siguientes:

i) La actitud enunciativa del narrador se distingue por adoptar este una perspectiva desacostumbrada, indirecta, frente a los hechos que narra.

Como ya señalé, este aspecto es transversal a toda la obra felisberteana. Por ejemplo, el punto de vista del narrador afectado de locura en el texto homónimo del Libro sin tapas. Un ejemplo más interesante de esta actitud enunciativa lo encontramos en el uso de una alegoría con ribetes críticos en el relato "Acunamiento" del mismo libro. El punto de partida es la llegada del fin del mundo a la Tierra, por lo cual un país crea un simulacro de este planeta: "Pero ellos fueron los únicos asombrosamente capaces de resolver el problema de precaverse: construyeron seis planetitas de cemento armado incluyendo las leyes físicas que los sostuvieran en el espacio" (Hernández, 2010, p. 55).

Siguiendo con este libro, veamos "Historia de un cigarrillo", que es en realidad la historia de una obsesión o, mejor dicho, es también la historia de la obsesión en torno al cigarrillo roto. Sin embargo, pa- 
reciera ser que el cigarrillo fuera un objeto cualquiera que permite al narrador pensar en su obsesión. Algo similar encontramos en los relatos en que el narrador parece centrado en el misterio, como en "El vestido blanco", donde este realiza un análisis detallado del problema que según él se produce al abrir las dos hojas de la ventana de la casa de Marisa, y "La casa de Irene", donde los objetos, las ventanas y el vestido, por un lado, y las manos y las sillas, por el otro, podrían bien constituir subterfugios narrativos que ayudan al narrador a pensar en lo que de verdad le importa, Marisa e Irene, respectivamente, y sus respectivos misterios. O todo no es más que un pretexto para pensar, o para escribir. Como destaca Jorge Monteleone en el prólogo de Los libros sin tapas (cfr. Hernández, 2010): el solo hecho de escribir, de lograr mantener la escritura como si fuera un hilo que se desprende del pensamiento, parece ser lo que causa la obra de Felisberto Hernández.

En estos casos, la actitud del narrador hace que todo el relato parezca una divagación para llegar al que sería el tema, o, por el contrario, hace que dicho tema parezca un pretexto para referirse a todo los demás. Tanto en "Acunamiento" como en "El vestido blanco", la imagen final que recupera el tema es un objeto en suspensión: en el primero, la Tierra acunando a la humanidad; en el segundo, el vestido blanco de Marisa.

Se puede también recurrir al tercer libro, La cara de Ana, cuyo primer relato, homónimo, contiene una suerte de preámbulo a la parte propiamente narrativa, en el que se dice:

Además de sentir todas las cosas y el destino parecido a las demás personas, también lo sentí de una manera muy distinta. Cuando sentía parecido a los demás, las cosas, las personas, las ideas y los sentimientos se asociaban ente sí, tenían que ver unos con otros y sobre todos ellos había un destino impreciso, desconocido, cruel o benévolo y que tenía propósito. [...] Otras veces me ocurría que ese comentario no me venía y empezaba a sentir las cosas y el destino de la otra manera, de mi manera especial: las cosas, las ideas, las personas y los sentimientos no tenían que ver unos con los otros y sobre ellos había un destino concreto $[\ldots]$. Y aunque estas cosas no tuvieran que ver unas con otras en el pensamiento asociativo, tenían que ver en la sensación disociativa, dislocada y absurda. (Hernández, 2010, pp. 87-88)

Este extracto podría estar resumiendo una suerte de poética del pensamiento del narrador felisberteano. Sin embargo, sería más preciso advertir un continuo desplazamiento de lo pesado a lo leve y viceversa, emulando o siguiendo el movimiento anímico del narrador: desde la distracción a la angustia o desde la impersonalidad a la angustia y de esta al humor, sin que ninguno de estos sentimientos sea un punto de partida y de llegada fijo. En este mismo relato el narrador hace una analogía entre el sentimiento de la "simultaneidad extraña" y el recorrido por las notas del piano, lo que interpreto como un movimiento hacia la levedad de la música:

\footnotetext{
Ninguna de estas cosas tenían que ver unas con otras; me parecía que cada una de ellas me pegara en un sentido como si fueran notas; que yo las sentía todas juntas como un acorde y que a medida que pasaba el tiempo unas quedaban tenidas y otras se movían [...]: todas las cosas me venían simultáneamente a los sentidos y éstos formaban entre ellos un ritmo; este ritmo me daba la sensación del destino, y yo seguía quieto, y sin el comentario de lo físico ni de lo humano. (Hernández, 2010, p. 90)
}

ii) Se presentan, en principio, cuatro tipos de temas: ii.i) un tema que suele recibir un tratamiento serio (la enfermedad o el destino, por ejemplo) aquí es sometido a procedimientos de análisis que disuelven su compacidad, convirtiéndolo en algo menos serio o menos grave; ii.ii) un tema más o menos trivial aquí es sometido a un tratamiento serio; ii.iii) un tema no habitual como tema literario, que se vincula más bien al plano de las ideas y que suele recibir un tratamiento filosófico; ii.iv) un tema cuyo carácter ficcional está puesto de relieve, debido a la imposibilidad de realizarse en el mundo físico.

Un ejemplo del cuarto tipo (ii.iv), lo encontramos en el texto homónimo de Libro sin tapas. Aquí el tema es el juicio que el jurado de los dioses entabla al dios ya muerto de la última religión, que es condenado por su egoísmo a contemplar la Tierra, para lo cual es amarrado al anillo de Saturno. En esta posición, el 
dios castigado se dedica básicamente a analizar los problemas de la Tierra.

También en "La piedra filosofal" hay manifestación de ii.iii y ii.iv, pues se comienza anunciando que se están "haciendo los cimientos para la casa de un hombre bueno" (Hernández, 2010, p. 58) y la piedra filosofal explica a la piedra normal su teoría de la graduación de lo duro y lo blando. Pero al final del relato, lo serio de este discurso se resuelve en algo nimio, que es la función que la piedra filosofal puede cumplir en una construcción al ser vista como piedra normal:

La Piedra Filosofal iba a decir otra de las leyes de la Teoría de la Graduación. Un albañil creyó muy oportuna su forma cuadrada, y sin darse cuenta la interrumpió. Pero ésta sirvió muy bien para los cimientos de la casa del hombre bueno. (Hernández, 2010, p. 62)

Cabe señalar que, en estos dos últimos ejemplos, la clave del tema de los relatos planteado en el título o al principio del texto, se explica al final.

iii) El aligeramiento del lenguaje a través del uso de imágenes que canalizan los significados de modo tal que estos se ven afectados en su consistencia. Preferentemente, estas imágenes concurren todas en un mismo sentido, para dar una visión de la paridad de las cosas del mundo (la primera acepción de Calvino), ya que estas pueden concurrir en un mismo plano para crear la imagen de un concepto o un objeto. Obviamente, aquí la cuestión de la analogía, la comparación y la metáfora es esencial, sobre todo en autores como Felisberto Hernández (véase Fell, 1977; Corona Martínez, 2010).

Encontramos una analogía interesante, expresada en términos comparativos, en el relato "El vapor" (La cara de Ana), donde la angustia se le presenta al narrador "parecida a la de los niños mimados cuando han vuelto de pasear y les sacan el traje nuevo" (Hernández, 2010, p. 100). Esta analogía produce en quien la piensa el sentimiento de hilaridad o, como él mismo dice: "Me reí de esta ridiculez y traté de reaccionar, pero entonces caí en otra angustia mucho más vieja, más cruel y que por primera vez vi que era de una crueldad ridícula" (Hernández, 2010, p. 100). Vemos aquí los movimientos continuos del ánimo ha- cia los opuestos, de lo que tiene peso - en este caso, la angustia - a la risa, y, posteriormente, a la sensación de experimentar algo ridículo, para luego pasar a la sensación de experimentar algo cruel, que no tarda en aparearse y manifestarse como "crueldad ridícula". El movimiento más claro desde lo pesado a lo sin peso y de este a lo pesado de nuevo, se observa en estas imágenes que contienen una analogía relevante para lo que estamos tratando aquí, envuelto todo en la sensación de distracción general del protagonista como actitud ante el mundo y que relacionamos con la mirada oblicua sobre las cosas (rasgo 1). Cito en extenso el pasaje que más importa:

Sin darme cuenta me había parado en la punta del muelle como si ya fuera a subir al vapor, aunque éste todavía no se veía venir. Y sin darme cuenta caí en la impersonalidad: parecía que todo el cuerpo se me hubiera salido por los ojos y se me hubiera vuelto como un aire muy liviano que estaba por encima de todas las cosas. Pero de pronto la angustia me volvió a atacar y la sentí más precisa que nunca en su cruel ridiculez. La sentí como si dos avechuchos se me hubieran parado uno en cada hombro y se me hubieran encariñado. Cuando la angustia se me inquietaba, ellos sacudían las alas y se volvían a quedar tan inmóviles como me quedaba yo en mi distracción. Ellos habían encontrado en mí el que les convenía para ir donde yo hubiera querido ir solo. Habían descubierto mi placer y se me colaban, llegaban hasta donde iba mi imaginación y no me dejaban ir al placer libre de la impersonalidad. (Hernández, 2010, pp. 100-101)

Hay aquí dos imágenes que comentar. La primera, referida a la caída en la impersonalidad expresada como la salida del cuerpo por los ojos y su transformación en "un aire muy liviano que estaba por encima de todas las cosas", la vinculamos al aligeramiento del lenguaje, ligado ahora a la imagen aérea, tanto como a la mirada indirecta del protagonista sobre cosas y hechos, y a la metamorfosis de lo pesado en lo leve, pues algo pesado como la personalidad se escapa a través de las cuencas en estado de aire muy liviano. La segunda imagen constituye un símil y, como tal, pretende producir un acercamiento entre dos cosas, donde una es difícil de dar a conocer y por ello es expuesta a través de otra más accesible. No obstante, 
en el caso de Felisberto (y de la prosa vanguardista, en general), la regla del símil de presentar lo desconocido a través de lo conocido aparece subvertida, pues el segundo elemento tiene su origen no en el conocimiento general del mundo, sino en la subjetividad del personaje, por lo que se vuelve arbitraria y enigmática, redoblando la dificultad de acceder al primer término.

En síntesis, al tratarse de un intento de explicación en lenguaje figurado de un sentimiento (la angustia), la figura que se instala resplandece como figura, pero no como explicación. Claude Fell diría: "el comparante predomina sobre el comparado" (1977, p. 107). En este caso, la imagen de las aves en los hombros del personaje traduce en figura con peso y consistencia algo inasible como la angustia. Con todo, la figura de los dos avechuchos cobra vida al sostener una actitud, se convierte en un objeto sobre los hombros que limita la libertad del sujeto, y nos permite acceder a un significado: la angustia se experimenta como un ave que no vuela, como un peso que se mueve si el sujeto se mueve, como si fuera un parásito o, mejor, un ave carroñera, vigilante como los cuervos que merodean ante un animal herido. El personaje lo explicita: la angustia frena la impersonalidad, que es y a un cierto ritmo musical entra en afinación con las otras cosas de la casa, logrando representar la paridad de todas las cosas.

La sensación de lo nuevo, de ver nuevamente y con otros ojos las cosas de siempre, que asalta al personaje en relación con su propia forma de tocar el piano, la explica así: "En ese momento me daba cuenta que a todo eso contribuían, Irene, todas las cosas de su casa, y especialmente un filete de paño verde que asomaba en la madera del piano donde terminan las teclas" (Hernández, 2010, p. 73). Al fijar la mirada en las sillas, el pensamiento se hace concreto; sin embargo, de lo que se trata es de descubrir una nueva afinación entre las cosas: "las sillas entre ellas se entendían" (Hernández, 2010, pp. 74-75). Puede decirse entonces que mientras el pensamiento está fijo en el "misterio" de Irene, se impone la densidad de lo abstracto, que a su vez se aligera al centrar el pensamiento en objetos nimios: las manos, las sillas, un paño, las teclas. La consistencia de las cosas no llega a producir el efecto de consistencia, pues hay entre ellas una afinidad que actúa como ese aire liviano que pasa por encima. En el fondo, nos encontramos en "La casa de Irene" y en "La barba metafísica", con el mismo fenómeno, don-

\section{Fesliberto Hernández juega aquí con las posibilidades de un lenguaje figurado sostenido en la geometría, despojándolo de todo viso de pesadez. Lo leve es hermano de lo lúdico y funcio- na como su lenguaje. La geometría, lo lúdico y la levedad son señas de la obra vanguardista.}

el placer por donde el personaje se libera de sí mismo. La figura de los avechuchos parados en los hombros nos resulta pesada y contrasta con las imágenes de levedad que funcionan como emblema de esta, de las que la obra felisberteana no está exenta y que siempre aparecen en movimiento.

"La casa de Irene" (Libro sin tapas) también permite ejemplificar los rasgos 3 y 9 , como se observa en estas citas: "Primero, mientras conversaba, no podía dejar de mirar las formas tan libres y caprichosas que iban tomando los labios al salir las palabras" (Hernández, 2010, p. 73); "Cuando terminó de conversar, empezó a tocar el piano de nuevo, y las manos se movían tan libre y caprichosamente como los labios. Las manos eran también muy interesantes y llenas de movimientos graciosos y espontáneos" (Hernández, 2010, p. 73). Esta levedad ligada a los movimientos de los grandes temas como el misterio y el destino, se atomizan en objetos nimios - la barba, en el segundo texto - que permiten que un tema serio sea abordado desde lo trivial y, en un movimiento alterno, que un tema trivial sea abordado desde lo profundo o lo serio.

Otra forma de aligeramiento del lenguaje se observa en Felisberto gracias a la plasticidad y al uso de diminutivos para sustantivos que usualmente no los requieren, por ejemplo, en los "planetitas" en "Acunamiento" y "la esperancita" en "Libro sin tapas". Al aplicar diminutivos a sustantivos que nombran entidades no objetuales (la esperanza) o a objetos que resisten dicha aplicación sugiere no solo la intención de poner en paridad todas las cosas del mundo, sino que el deseo de singularización o desfamiliarización del lenguaje, rasgo característico de las vanguardias. 
iv) La disolución de la compacidad del mundo a través de la percepción de pequeñas y sutiles entidades que lo componen, que están en movimiento, se desplazan por el espacio y tienen poder de transformarse. Esta disolución de la compacidad del mundo puede producirse por una descripción detallista o el relato, también detallista, y que comporta un alto grado de abstracción, de un razonamiento o de un proceso psicológico (la segunda acepción).

La percepción de lo leve que actúa en el mundo se presenta en Felisberto Hernández a través de imágenes de lo imperceptible, como ocurre al final del relato "Acunamiento": "Igual que los niños dormidos cuando los acunan, los peregrinos no se daban cuenta [de] que la Tierra los acunaba. Pero la Tierra era maravillosa, los acunaba a todos igual, y les daba el día y la noche" (2010, p. 57). Otros ejemplos lo constituyen la percepción del espíritu de los objetos, como en "Historia de un cigarrillo" y "La casa de Irene", ambos de Libro sin tapas.

Del relato que inicia el primer libro, titulado como este, "Fulano de tal", puede decirse que la levedad tiene un punto de partida en la índole del problema que se narra y en la índole del narrador. En ambos casos se trata de la locura, pero esta no es presentada de la manera dramática que tal tema y tal narrador hacen esperable de acuerdo con nuestra experiencia del mundo. Podría decirse que lo que hace leve esta perspectiva es la descomposición del problema que el personaje cree que es la causa de su locura, esto es, su dificultad para entretenerse. La entretención es un problema auscultado una y otra vez por el narrador, quien divide el mundo entre los que se entretienen los cuerdos - y los que no lo logran - los locos-, así como distingue entre los "entretenidos" productivos y los receptivos. Pero el narrador también examina lo que él llama las "trampas del entretenimiento", entre las cuales se encuentran principalmente, el arte y la ciencia. Estas trampas adquieren en su discurso un grado de concreción muy alto debido a su literalización, pues son trampas que, como las que se usan para atrapar ratones, ostentan un pedazo de queso:

Tanto en las trampas del arte como en las de la ciencia, hay grandísimas emociones, y la emoción es, precisamente, el queso de las trampas de en- tretenerse. Pero yo ya probé el queso de todas las trampas y me da en cara: he aquí mi tragedia de la locura de no entretenerme. (Hernández, 2010, p. 38)

De acuerdo con ello, el personaje opta por casarse y tener hijos, acciones a las que llama trampa de entretenimiento que en vez de queso tiene carne que chorrea sangre. Como se observa, en lo recién citado se encuentra la manifestación de lo grave sin peso, pero también lo contrario, es decir, lo leve con peso. Esto es posible en virtud de los dos movimientos que realiza el sujeto, el de abstracción de lo concreto y el de concreción de lo abstracto, de tal manera que algo general y vago, sin mayor definición esencial, como lo es el hecho de entretenerse, es analizado en los diversos componentes, lo que lo hace adquirir una extraña consistencia.

v) La unión de una concepción atomista del universo con la percepción de la unidad de todas las cosas, que conecta macrocosmos y microcosmos, lo sutil y lo grueso, lo pesado y lo leve.

Ejemplos de este rasgo los encontramos en tres relatos, "La casa de Irene" y "La barba metafísica" de Libro sin tapas, y "La suma" de La cara de Ana, pues en ellos el narrador comienza por visualizar fragmentos para llegar a una idea de totalidad. Cabe hacer notar que, en los tres casos, la percepción tiene como objeto un ser humano. Veamos lo que dice el narrador en "La suma":

De pronto vi a mi compañero como si fuera una suma que por primera vez le hiciera el total. Eso me produjo una sensación y una reacción tan rara que me reí toda la noche. $\mathrm{Al}$ verlo un poco de lejos le encontré proporciones que antes no había visto: era alto, delgado, la cabeza elegantemente un poco grande en relación al cuerpo [sic], y la nariz que de cerca era demasiado grande, de lejos era una pincelada muy ocurrente. Estaba solo, miraba para todos lados con disimulo, y aparentaba estar distraído. El total de la suma era que al mismo tiempo que su carácter, su actitud escondía sus pensamientos, su cuerpo delgado despistaba sus dificilísimas digestiones. Además de eso tenía un nombre místico: se llamaba Salvador. (Hernández, 2010, p. 96) 
Como se observa, esta actitud esconde una suerte de cosificación del sujeto, que va acompañada de una hilaridad que devuelve la levedad a la imagen.

vi) Puesto que las entidades pequeñas generan zonas de contacto entre ellas y entre las cosas, debido a su desplazamiento, se produce un equilibrio gravitacional de los cuerpos en el espacio, que se expresa a menudo con imágenes aéreas o de cuerpos en suspensión.

Una imagen que desafía la ley de gravedad y que no está exenta de humor es el castigo impuesto al dios pecador en el Libro sin tapas, quien es amarrado al anillo de Saturno para que deje de pensar en sí mismo y visualice los problemas de la Tierra. Esta imagen de cierto peso se aligera a medida que el dios castigado logra distraerse y mover sus piernas, como en el apartado III:

Ya no podía más de aburrido, de pensar siempre lo mismo sin hallar solución. A veces le venía una esperancita de solución y aprovechaba a ponerse contento antes que se diera cuenta [de] que no había encontrado solución. Entonces, durante la alegría de la esperancita movía alternativamente las piernas. (Hernández, 2010, p. 48)

vii) La presentación de la melancolía y el humour que nacen directamente de una actitud de quitar peso a lo grave, normalmente, a través de una perspectiva distanciada de los hechos.

Por ejemplo, "Cosas para leer en el tranvía", especialmente "Juegos de inteligentes" y "Teoría simplista de las almas gordas", de Fulano de tal. Puede decirse, en todo caso, que toda la obra de Felisberto está impregnada de un fino humor, un humor leve.

viii) La presencia de una imagen figurada y figurativa de levedad que cobra un valor emblemático por su capacidad de producir una fijación o visualización (la tercera acepción).

Un ejemplo interesante es el de la imagen objetual y, por lo tanto, de carácter concreto, a la que recurre el narrador de "Libro sin tapas". Se trata de la figuración de la Tierra como cascabel o sonajero de bebé, como se explicita en el apartado IX. Con esta imagen, el personaje - el dios castigado - se representa no solo la Tierra, sino que también pretende explicarse su movimiento y el accionar de la humanidad:
Cuando lograba detener los "porqués", la Tierra le parecía maravillosa; le parecía un juguete ingeniosísimo; la encontraba parecida a esos sonajeros de los niños que es necesario que los muevan para que suenen: la Tierra se movía y por eso los hombres tenían acción. Tal vez si la Tierra se detuviera ellos también. Pero no se podía asegurar nada, era un juguete muy complejo. Hubiera deseado, igual que los niños, romperlo, ver cómo era interiormente y romperle el porqué. (Hernández, 2010, p. 51)

Por su parte, "La envenenada", homónimo del cuarto libro, es uno de los relatos más acabado, pues posee mayor narratividad. Su tema es doble, por un lado, la búsqueda de un literato de un "asunto" o tema para escribir recibe un tratamiento irónico y distanciado, que no deja de constituir una mirada penetrante hacia las sensaciones y actitudes del literato. El otro tema es la mujer envenenada o el encuentro entre el literato y el cadáver expuesto al borde de un arroyo. La forma en que coinciden ambos temas resulta obvia: al hallar el literato el cuerpo de la envenenada ha encontrado también su asunto.

Como Calvino, el literato siente el peso del vivir, lo siente específicamente en las piernas, pero en lugar de escribir sobre ello, Felisberto Hernández trivializa esta angustia metafísica en la búsqueda del "asunto" para la escritura. Mientras se acerca al lugar donde se encuentra la envenenada, el espíritu del literato "oscilaba entre conservar su yo y abandonarse a la curiosidad: parecía un elástico que se estirara y se encogiera" (2010, p. 108). Finalmente, se acerca. La descripción de la envenenada corre por cuenta del narrador, tal es la distancia que este ha puesto entre su voz y la del personaje. Lo que aquí nos importa es la última imagen, una de las que realiza con éxito eso que Calvino llama la imagen emblemática de levedad. Refiriéndose a uno de los brazos de la mujer, el narrador dice:

[...] estaba muy separado del cuerpo, y desde el codo hasta el puño había quedado parado como un pararrayo; el puño no estaba cerrado del todo, y de entre los dedos que estaban crispados y juntos, salía un pañuelito que flameaba con la brisa. (Hernández, 2010, p. 108) 
Esta imagen está atravesada por esa, quizá después de todo, no tan extraña conjunción entre el humor y la melancolía, sentimiento que a su vez se conjuga con una escena cuya tragicidad se aliviana dado el componente contradictorio y hasta antitético que se asoma en la imagen, pues, ciertamente, el pañuelo movido por la brisa representa allí la persistencia de la vida en un gesto mínimo. El contraste muerte-vida, manifestado en la oposición peso-levedad, es otra de las formas en que Felisberto Hernández se acerca a la prosa de Luciano, de Rabelais y de vanguardistas como el chileno Juan Emar.

En el relato siguiente del mismo libro, "Ester", encontramos una imagen similar, aunque el contraste no resulta tan marcado; al observar el narrador a las muchachas que pasan, en un movimiento perceptivo y volitivo como el del narrador proustiano, una se le desprende de las demás, vale decir, se le individualiza, y por ello le da un nombre, Ester, de quien dice: "Caminaba ligero siempre, y al pasear entre las otras, las otras parecían plantas que se movieran por una brisa suave" (Hernández, 2010, p. 115). Vemos cómo la prosa felisberteana goza de una gran plasticidad, que parece reservada sobre todo a las imágenes de levedad, emparentadas con la vitalidad. Refiriéndose de nuevo a Ester, dice:

[...] tal vez desafiara la vida, pero en ese momento yo no le hubiera llamado vida a lo activo y misterioso de las personas y los hechos: en aquella tarde yo le hubiera llamado vida al aire que estaba alrededor de las plantas y de los bancos de la plaza. Ella desafiaba tal vez a eso, y las puntas de su saco abierto se doblaban un poco para atrás al caminar ligero. (p. 116)

Estas imágenes tienen otro rasgo dominante y es el hecho de que contribuyen al "aligeramiento del lenguaje", porque están allí para expresar una idea o una intuición e incluso un concepto: "Al estudiar - dice de Ester-, no le preocuparía no entender algunas cosas, y éstas le quedarían tan espontáneamente dobladas para atrás, como las puntas de su saco al caminar ligero" (Hernández, 2010, p. 116).

La angustia del narrador frente a la indiferencia de Ester de nuevo aparece expresada con una comparación que remite a un comportamiento infantil, como en "El vapor". En ambos casos debemos interpretar el recurso a la molestia - quizás angustia - infantil como una forma de expresar levedad en la angustia del adulto: "[...] mi angustia estaba nada más que en el deseo de empezar todo de nuevo como cuando los niños arrancan la hoja de la plana en que una letra les ha salido torcida" (Hernández, 2010, p. 118). Pero como constata luego, la indiferencia de Ester no es acorde con ese tipo de angustia, pues se revela como una "descoincidencia" total. Por eso la última imagen del cuento se vuelve algo pesada, inicialmente, ya que el narrador detrás de Ester expresa esta distancia con la imagen de un ferrocarril donde él siente el aire que parece emanar de ella para doblarle el sombrero y el saco. Posteriormente, al darse cuenta de su propio desprendimiento sentimental, refrenda la coexistencia de lo pesado y lo leve: "No me di cuenta cuándo fue que mi destino tuvo la esquina: debíamos haber parecido que el ferrocarril se enloquecía y que yo era un vagón que se desprendía y tomaba por otra vía" (Hernández, 2010, p. 119).

ix) La concepción del mundo como un lenguaje, es decir, como combinatoria de cosas-signos más o menos cifrada.

A primera vista, este rasgo o tercera acepción de la levedad no estaría presente en la obra felisberteana que estamos analizando. Esto es así en sentido estricto. Sin embargo, podemos anotar que la idea de una afinación entre las cosas, y a veces entre las cosas y los personajes, va constituyendo una suerte de lenguaje, en el que se emite algún tipo de señal para un receptor, que es el narrador.

A este respecto, no puedo dejar de recordar el concepto de "afinación" como lo plantea Juan Emar (2014), quien lo elabora como parte de su pensamiento sobre la comprensión del mundo, y donde "afinación" se hace sinónimo de "afinidad", dentro de una concepción del mundo como lenguaje:

[...] he llamado al hombre un receptor y al universo un transmisor. Cuando hay afinidad entre ambos, hay comprensión. Un hombre debidamente desarrollado no irá recibiendo del universo más que aquello con lo cual se afina. Y el progreso es normal. Pero la mayoría no procede así. Desafinados contemplan el universo. (Emar, 2014, p. 67) 
De esta manera, para comprender y participar en el mundo sería preciso atender al lenguaje con el que el universo se expresa, vale decir, a las afinaciones: "Existen estas afinidades en cualquier mundo. A cada instante estamos solicitados por ellas, mas son tan pocas las veces que nos detenemos ante estos sutiles llamados" (Emar, 2014, p. 42). En una primera instancia, entonces, tanto para Emar como para Felisberto Hernández el concepto de "afinación" tiene como significado el que adquiere en la práctica musical, es decir, hacer concordar los instrumentos en cuanto al tono, y, en segunda instancia, la "afinación" equivale al lenguaje del mundo, en el caso emariano, y de la conciencia que observa de manera "especial", en el caso de Felisberto.

Como se pudo observar, algunos textos felisberteanos reúnen varios de los rasgos de la levedad. Uno de los más completos es "Genealogía", de Libro sin tapas, que presenta los primeros ocho. El tema de este relato es el paseo que realiza una circunferencia sobre una línea horizontal infinita. Durante este paseo, aparece un triángulo, de forma pesada y rígida. La circunferencia se transforma en elipse, lo que da pie al triángulo para aligerarse en una forma que a él le parece más sutil, un pentágono. Posteriormente, decide volverse un "alegre cuadrilátero" (Hernández, 2010, p. 67). Ambas figuras, la circunferencia convertida en elipse y el ahora cuadrilátero, tratan de dominar su inercia. Se producen luego unos eclipses; durante el último, la elipse vertiginosa y veloz queda encerrada en el cuadrilátero. Pero esta no será la última transformación, veamos cómo termina el relato:

Cuando fueron viejos no se les importó más de la forma y la elipse se volvió una circunferencia encerrada en un triángulo. Marcharon cada vez más lentamente hasta que se detuvieron. Cuando murieron el triángulo desunió sus lados tendiendo a formar una línea horizontal. La circunferencia se abrió, quedó hecha una línea curva y después una recta. Los dos unidos fueron otra línea superpuesta a la que les sirvió de camino. Y así, lentamente, se llenó el espacio de muchas líneas horizontales infinitas. (Hernández, 2010, p. 68)

Felisberto Hernández juega aquí con las posibilidades de un lenguaje figurado sostenido en la geometría, despojándolo de todo viso de pesadez. Lo leve es hermano de lo lúdico y funciona como su lenguaje. La geometría, lo lúdico y la levedad son señas de la obra vanguardista.

\section{Conclusiones}

Puede sostenerse que la primera narrativa de Felisberto Hernández ostenta, como una de sus propiedades, la levedad. Esta propiedad ha proporcionado una de las formas que encontró esta obra para sostener su autonomía como obra artística, pues, por su afirmación temática y de perspectiva o actitud narrativa ante los hechos, refuerza el carácter de idea y de ficción del universo narrado. Con todo, esta conclusión no sería justa si no necesitara reconocer que esta obra se realiza como narrativa estructurada de acuerdo con el binomio levedad-pesadez. Los finales de los textos suelen atestiguar esta ambivalencia con su resolución inesperada que rompe la expectativa que la propia historia o el hilo de la narración ha creado. Si existe, como dice Calvino, una literatura de la levedad, Felisberto, en su primera etapa y con toda su ambivalencia, figura entre sus autores. Muchos de estos rasgos persistirán en su obra posterior, en resoluciones narrativas distintas, que requieren sus propios análisis. Por ahora, pongo énfasis en la singularidad de una obra que, sin dejar de ser única, "se parece" a la de Luciano, Rabelais, Cyrano y Swift, tanto como a la de Macedonio y Emar. Todas ellas son, cada una en su modo singular, literaturas de la levedad.

Por último, es necesario destacar que Calvino no está preocupado del arte de vanguardia, sino de un tipo de literatura - la de la levedad - cuya presencia constata a lo largo de una historia general de la literatura y pone en contacto diferentes obras de variados géneros, de países y épocas distintas. Al localizar e historizar la categoría de levedad en la narrativa latinoamericana de vanguardia se abre una zona de contacto entre esta última y una cierta tradición de escritura que se desprende del recorrido histórico y de los ejemplos presentados por Calvino. En tal sentido, el concepto de levedad permite restituir un componente de las relaciones entre la vanguardia y las tradiciones del pensamiento y de la producción literaria de la Europa de siglos pasados, donde encontramos a Lucrecio y Luciano entre los nombres más antiguos, y a Cyrano y Shakespeare entre los modernos. 


\section{Referencias bibliográficas}

Calvino, Í. (2001). Seis propuestas para el próximo milenio (3. ${ }^{a}$ ed.). Madrid: Siruela.

Calvino, Í. (2009). Prólogo. Felisberto Hernández es un escritor que no se parece a ninguno. En F. Hernández. Nadie encendía las lámparas, Trad. de Mario Capurro Parodi (pp. vii-ix). Madrid: RM. Verlag.

Corona Martínez, L. (2010). La narración digresiva: las imágenes en Felisberto Hernández. Una revisión de los procedimientos. Cuadernos LíRICO, 5, 111-123. https://doi.org/10.4000/lirico.405

Díaz, J. P. (Ed.). (1988 [1981]). Introducción. En F. Hernández, Obras completas, Introducción, ordenación y notas de José Pedro Díaz (pp. 5-35). Montevideo: Arca-Calicanto.

Emar, J. (2014). Cavilaciones. Santiago: La Pollera ediciones.

Fell, C. (1977). La metáfora en la obra de Felisberto Hernández. En A. Sicard (Ed.), Felisberto Hernández ante la crítica actual (pp. 103-117). Caracas: Monte Ávila Editores.

Fraga de León, R. (2003). Felisberto Hernández. Proceso de una creación. Lima: Pontificia Universidad Católica del Perú.

Hernández, F. (1983). Obras completas, Edición de María Luisa Puga, 6 volúmenes. Ciudad de México: Siglo Veintiuno Editores.

Hernández, F. (2010). Los libros sin tapas, Prólogo de Jorge Monteleone. Buenos Aires: El Cuenco de Plata.

Martínez, A. (2007). La singular vanguardia de Felisberto Hernández. Arrabal, 5-6, 131-137.

Monteleone, J. (2015). El otro yo del pianista. En F. Hernández. Narrativa completa, Estudio crítico de Jorge Monteleone; María del Carmen González (pp. 7-63). Buenos Aires: El Cuenco de Plata.

Rodríguez Amaya, F. (2017). Nadie encendía las lámparas de Felisberto Hernández y los cinco postulados de las Lecciones americanas de Ítalo Calvino. En F. Rodríguez Amaya (Ed.), La política de la mirada. Felisberto Hernández hoy (pp. 149-166). Milán: Ledizione. 